\title{
Lukasz Dominiak
}

Faculty of Political Science and International Studies

Nicolaus Copernicus University in Torun

\section{Prenatal Harm and Theory of Identity}

$15 / 2013$

Political Dialogues

Keywords: theory of identity, prenatal harm, abortion law, women's rights, non-identity problem, the interest view, essentialism, causality, Different People Choice, Same People Choice

\section{Summary}

Although in many Western legal regimes women have a right to terminate pregnancy on request at the relatively late stage of gestational age of the foetus, a remarkable paradigm shift in law concerning women's reproductive freedom and status of the foetus has been noticed since the 1990s. This evolution has occurred outside the abortion framework in a form of wrongful life suits, preconception and prenatal torts or foetal homicide laws. According to some commentators it has created a conspicuous discrepancy between status of the foetus in the abortion context and its standing in other branches of law, particularly in so-called prenatal harm lawsuits. In this paper I am going to analyse theoretical background that bear prenatal injury lawsuits out. The core thesis of the paper is the contention that any adjudication in prenatal harm lawsuits presupposes some theory of identity. This in turn means that plausibility of these adjudications depends not only on their consistency with our moral intuitions but also on the plausibility of a given background theory that endorses these adjudications. I identify the theory of causality as the main background theory of the concept of prenatal harm and argue that it is structurally unable to justify it; what is necessary for such a justification is the theory of identity.
In this paper I shall critically scrutinise the Bedingung der Moeglichkeit of the prenatal harm concept. I hypothesise that any consistent idea of prenatal harm must presuppose some theory of identity. To boot, I claim that there is a specific group of theories for which justification of prenatal harm concept without presupposing a theory of identity is of the greatest importance because these theories are strongly engaged in the defence of women's rights, especially right to terminate pregnancy on demand up to some point in time, usually the 24th week of gestational age of the foetus. According to these theories, with an outstanding position of the so-called interest view amongst them, the apparent inconsistency between status of the foetus within the law that recognises prenatal harm on the one hand and abortion law on the other can be overcome only by abstracting from the question of identity. Harming the foetus in a minor way should be legally forbidden not because foetus is a human person - the same person as the future child developed from this foetus - but because it will cause harm to the future person that will be metaphysically distinct from this foetus.

\section{What Is Wrong with Prenatal Harm?}

What is wrong with prenatal harm? For the proponent of the right-to-life position the answer is quite simple: nothing at 
all. Since foetus is a human person - the same person as the future child - harming it should be punished analogically to harming a child. This question, however, is getting complicated when one is not the right-to-life proponent and wants to simultaneously protect the women's right to abortion and punish them and other parties for inflicting prenatal harm.

In the United States "several judges have expressed the view that recognition of prenatal wrongful-death suits conflicts with the right to abortion. One court maintained that it is 'incongruous' to allow a woman the constitutional right to abort and yet hold a third party liable to the foetus for merely negligent acts (...) Conservatives see hypocrisy in recognising prenatal wrongful-death actions while also allowing abortion; liberals worry that recognition of prenatal wrongful death will threaten women's rights of reproductive choice" (Steinbock 2011, p. 122-123).

This inconsistency is even more jarring when one wants to justify punishing women, doctors or others for inflicting minor disability on a foetus and at the same time wants to grant women the right to abort the foetus. Our considered moral judgement is utterly against this solution since we believe that to terminate life is worse than to harm somebody in a minor way.

\section{Can We Overcome the Inconsistency?}

According to the interest view this apparent inconsistency and also predicament for the proponents of the reproductive freedom can easily be overcome. The key issue here is to dismiss the premiss which this incongruence is dependent on, namely the theory of identity and all debates that surround this question. To put it more analytically, the quandary with prenatal harm can occur only when two conditions pertaining to the theory of identity are fulfilled: first, the foetus must be the same entity as the future child; second, it must be the foetus who is harmed in prenatal harm acts. Additionally, one could say that the third condition here is that it is the foetus that is harmed by abortion but this third claim can be logically derived from the first two.

So, Bonnie Steinbock writes: "The interest view denies moral and legal status to the early-gestation foetus, providing part of the justification for legal abortion. However, acceptance of the interest view does not preclude prenatal torts, that is, civil suits brought against physicians whose negligence causes children to be born with serious injuries. Although the harm is inflicted prenatally, when the child is a foetus, it is not the foetus, but surviving child, who is affected and wronged by the negligence. Allowing surviving children to recover for injuries inflicted prior to birth in no way implies that preconscious foetuses have interests, rights, or moral or legal status. There is no contradiction in a legal system that both allows for abortion and allows recovery for prenatal torts" (Steinbock 2011, p. 109).

The interest view explicitly says that the second condition saying that it is the foetus who is harmed in prenatal harm acts is unfulfilled. Foetuses cannot be harmed neither by abortion nor by negligent acts because for an entity to be harmed it must have interests. To have 
interests in turn an entity must be conscious; "without conscious awareness, beings cannot have interests" (Steinbock 2011 , p. XIV) and exactly for that reason "preconscious foetuses do not have interests" (Steinbock 2011, p. XV). In this paper I will not discuss if Steinbock's concept of interests, consciousness and foetal development is sound or unsound. I deal here only with metaphysical underpinnings of the concept of prenatal harm in the context of liberal abortion law.

So, what about the first condition, namely the claim that foetus must be the same entity as the future child? Is this condition also abandoned by the interest view? This is where things start to get interesting.

\section{The Necessity of the Theory of Identity}

First and foremost, there is no doubt that if the foetus was the same entity as the future child that would weaken women's reproductive rights; killing the foetus would mean killing the same kind of being as you and me. But is foetus the same entity as future child according to the interest view?

As Bonnie Steinbock writes, the interest view proponent is "a sceptical agnostic about essentialism" (Steinbock 2011 , p. 76) according to whom the problem of prenatal harm and abortion law can be resolved without recourse to the theory of identity. This position of the interest view is strengthened by further Steinbock's considerations on preconception torts according to which "duty of care can exist even before the conception of the individual injured by the negligence" (Steinbock 2011, p. 111). What is important for the interest view is therefore the theory of causation, not the theory of identity. "One relevant factor is causation" (Steinbock 2011, p. 111). Commenting on Jorgensen v. Meade Johnson Laboratories Steinbock writes: "Assuming that causation could be established, the fact that the injury resulted from preconception conduct was no reason for denying recovery" (Steinbock 2011, p. 112).

Does this causalistic solution work? I claim that it does not and that for the interest view or other Biological Causality Accounts the theory of identity is unavoidable. Let's conduct the following series of thought experiments:

\section{1) Main Thought Experiment}

Imagine that there is a woman in the 4th month of pregnancy who takes a pill that causes detrimental mutation in foetus' genes that in turn causes moderate mental disability in the future child (let's call this child Mark for the sake of convenience). Let's assume further that it happens in such a way "that causation could be established" and after thoroughgoing investigation we prove that mother's act caused genetic mutation which caused the disability. Can we conclude from this that this woman (the mother) harmed Mark?

Of course, we cannot answer such a question without some metaphysical background theory. To reach this conclusion we need something more than causation alone, we need some theory of identity that is able to rationally and justifiably demonstrate that mother's decision does not represent what Derek Parfit calls Different People Choice (Parfit 
1987 , p. 355-356) because if it does, then mother's action does not harm Mark but rather decides who is going to live, Mark or some other person. In a word, theory of identity constitutes Bedingung der Moeglichkeit of both the concept of prenatal or preconception harm and the answer to our question.

To explain it in a more detailed way let's stop our main thought experiment for a second and turn into classic thought experiment derived from Parfit's philosophy of identity and proposed by Jeff McMahan in his paper on wrongful life suits:

\section{2) The Preconception Case}

"A man and a woman are considering having a child but suspect that one of them may be the carrier of a genetic defect that causes moderately severe cognitive impairment. They therefore seek to be screened for the defect. The physician who performs the screening is negligent, however, and assures the couple that there is no risk when in fact the man is a carrier of the defect. As a result, the woman conceives a child with moderately severe cognitive impairments. Had the screening been performed properly, a single sperm from the man would have been isolated and genetically altered to correct the defect (...) Notice, however, that the probability is vanishingly small that the sperm that would have been isolated and altered would have been the very same sperm that in fact fertilised the egg during natural conception (...) In that case the child who would have been conceived had the screening been done properly would have developed from wholly different pair of gametes and thus in fact (...) have been different child from the retarded child who now exists" (McMahan 2004: 445).

\section{3) The Prenatal Case}

"A physician negligently prescribes a powerful drug for a woman who is in the eight month of pregnancy. The drug causes damage to the foetus's brain and the child to whom she gives birth is, as a consequence, moderately cognitively impaired (...) In that case, it seems clear that the retarded child who develops as a result of the brain damage is numerically the same child as the child who would have existed had the damage not been done" (McMahan 2004, p. 446).

Since we believe that life with moderate disability is worth living and undoubtedly better than non-existence, the child in the Preconception Case by definition could not have been harmed since the concept of harm presupposes making somebody worse off than he would have been if the act in question had not been performed. The Prenatal Case in turn involves harm to the child because inflicting disability on somebody is making him worse off, other things being equal.

Now explaining the statement that the interest view must have at its disposal some theory of identity that is able to rationally and justifiably demonstrate that mother's decision in our main thought experiment does not represent this sort of decision and action which Derek Parfit calls Different People Choice, we can say that McMahan suggests that the Preconception Case represents Different People Choice whereas Prenatal Case is thought of as being what Parfit calls Same People Choice. In 
a nutshell, Different People Choice is this kind of decision and action that affects identities of future people or affects "who the people are who will later live" (Parfit 1987, p. 355); if this sort of decision was made there would be different people in the world than there would be if this sort of decision was not made. Same People Choice on the other hand does not affect identities of future people; if this kind of decision was made there would be the same people in the world that there would be if this kind of decision was not made; in Same People Choice only life conditions of people involved change for worse or for better.

\section{In What Way Is the Theory of Identity Unavoidable?}

Let's come back now to our main thought experiment. Which of these two sorts of choices is represented by the woman's decision to take the pill that causes mental disability in Mark? My claim is that the answer to this question depends on the theory of identity we espouse. To put it more analytically, I claim that:

1) any distinction between Different People Choice and Same People Choice must rely on some theory of identity;

2) simple identification of the Preconception Case (or generally this sort of cases) with Different People Choice on the one hand and the Prenatal Case (or generally this sort of cases) with Same People Choice on the other as present in McMahan's theory is only partly justified;

3) since to establish the occurrence of harm in prenatal and preconception lawsuits it is inevitable to demonstra- te that allegedly unlawful act does not represent Different People Choice, any concept of prenatal harm must deploy some theory of identity; for that reason it is impossible to base the concept of prenatal harm only on the theory of causality. Let's now elaborate on each of these points.

1) To decide which of these two choices (Different People Choice or Same People Choice) we deal with, we must compare two lines of life: factual and counterfactual. In our thought experiment factual line of life is Mark with moderate intellectual disability; counterfactual line of life is person $\mathrm{X}$ without moderate intellectual disability that would have been born if the mother had not taken the pill. After defining the conditions of our comparison we have to ask ourselves: would Mark and person $\mathrm{X}$ be the same person or different people? For Mark and X to be the same person there had to be some relation between them that would make thinking about them as the same person justified. What kind of relation would it have to be? It would have to be the same relation that when holds between person A today and person A1 at some future time (in a year for instance) makes A and $\mathrm{A} 1$ the same person at different times. That would have to be the relation that constitutes personal identity over time but used for our comparison of factual person with counterfactual person. Let's call it $R$ relation. If $R$ relation held between Mark and $\mathrm{X}$ we would have to come to the conclusion that Mark and X would be the same person. So, the answer to the question which of these two choices (Different People Choice or Same People Choice) we deal with depends on the question if Mark and X could be ju- 
stifiably thought of as R-related. If yes, then we would have Same People Choice; if not, Different People Choice. But to answer the second question, namely if Mark and X could be justifiably thought of as R-related, we need some theory about what kind of relation constitutes personal identity, what kind of relation is $\mathrm{R}$ relation. It could be psychological continuity relation, the same genetic code, the soul, the same brain, the same organism, the same mind etc. But in any case we need some substantive theory of identity to justify our distinction between Different and Same People Choice. For the simple question: How to decide if Mark and X are the same person? The simple answer is: by consulting the theory of what it means to be the same person.

2) Derek Parfit came up with an idea that he called The Time-Dependence Claim, according to which: "If any particular person had not been conceived when he was in fact conceived, it is in fact true that he would never have existed" (Parfit 1987, p. 351). He qualified this claim to make it more uncontroversial and changed the phrase "when he was in fact conceived" to "within a month of the time when he was in fact conceived". The Time-Dependence Claim is not necessarily true since it depends on the theory of identity and there are theories of identity that differ or can differ considerably. If one believed that for R-relation to hold it is enough to have only small amount of the same genetic material, then the Time-Dependence Claim would not be true. It happened that for McMahan's theory of identity which says that $\mathrm{R}$ relation consists in the same embodied mind (McMahan 2002, p. 66-94) the Time-Dependence Claim holds to such an extent that considerable change in genetic material (different spematozoon, different ovum) would with a great probability (but not necessarily) result in different brain whereas moderately severe cognitive impairment is not big enough a change to talk about different people. So for McMahan the Preconception Case coincides rather with Different People Choice than with Same People Choice but for the proponent of for instance some variant of The Same Genotype Account of Identity even minor genetic change resulting in moderately severe cognitive impairment could constitute the instance of Different People Choice.

3) There are only two possibilities for woman's decision to take the pill that causes disability in Mark: it can be Different People Choice or Same People Choice. If it is Different People Choice then woman did not inflict any harm on her child since for this child there was no other option than to exist with moderate mental disability; otherwise the child would not have existed at all and there would have been different child there; and since non-existence is worse than life with moderate disability, there is by definition no harm involved in mother's decision. If it is the case then the concept of prenatal harm is spurious and so is legal recognition of it. So, for the proponents of prenatal harm law it is not enough to prove that there is a causality relation that holds between the act, the foetus, the future child and the disability. They have to show that the supposedly harmful act does not represent Different People Choice. But to do this they must harness some theory of identity that explains which differences 
between factual line of life and counterfactual line of life are adventitious and which are essential.

\section{Conclusions}

The interest view and other Biological Causality Accounts that try to justify both the concept of prenatal harm (it is possible to inflict harm prenatally but it is not the foetus who is harmed but future child) on the one hand and liberal abortion law (abortion on demand up to some point in time should be recognised as women's right since there is nobody there that could be harmed by abortion and there is no future child that could be the victim of prenatally caused harm) on the other without referring to metaphysical category of identity is structurally unable to do it. It cannot demonstrate that potentially harmful act inflicted prenatally or earlier does not represent Different People Choice; but without showing it the concept of prenatal harm in a sense promoted by the interest view is empty and unsound. Any consistent category of prenatal harm must be based on some theory of identity.

\section{Literature:}

McMahan J. (2004). Wrongful Life: Paradoxes in the Morality of Causing People to Exist, [in:] J. Harris (ed.), Bioethics, Oxford University Press, New York, p. 445-475.

McMahan J. (2002). The Ethics of Killing. Problems at the Margins of Life, Oxford University Press, New York.

Parfit D. (1987). Reasons and Persons, Oxford University Press, New York.

Steinbock B. (2011). Life Before Birth. The Moral and Legal Status of Embryos and Fetuses, Oxford University Press, New York. 